\section{What is already known on this topic}

Testing for human papillomavirus could improve the management of women with borderline or mildly dyskaryotic smear results

Human papillomavirus testing for borderline cytology and colposcopy for women positive for human papillomavirus has greater sensitivity to detect cervical intraepithelial neoplasia grades 2 and 3 than repeat cytology

\section{What this study adds}

Triaging women on the basis of testing for human papillomavirus is feasible during cervical screening

Such testing in pilot studies in England led to reduced rates of repeat smears but increased referrals for colposcopy
Contributors: SM led the evaluation team and is the guarantor. $\mathrm{AG}$ and RL participated in the evaluation. MV and JP contributed to the design of the study. HK contributed to the design of the study and chaired the steering group for the pilot studies.

Funding: Department of Health Policy Research Programme.

Competing interests: None declared.

Ethical approval: Not required.

1 Cuzick J, Sasieni P, Davies P. A systematic review of the role of human papilloma virus testing (HPV) in the cervical screening programme. Health Technol Assess 1999;1-196.

2 Rana DN, Marshall J, Desai M, et al. Five-year follow-up of women with borderline and mildly dyskaryotic cervical smears. Cytopathology 2004;15:263-70.

3 IARC Working Group on the Evaluation of Carcinogenic Risks to Humans. Human papillomaviruses. In: IARC monographs on the evaluation of carcinogenic risks to humans. Lyon: IARC Science Publications, 1995

4 Cuzick J, Szarewski A, Cubie H, et al. Management of women who test positive for high-risk types of human papillomavirus: the HART study. Lancet 2003;362:1871-6.

5 Schiffman M, Solomon D. Findings to date from the ASCUS-LSIL triage study (ALTS). Arch Pathol Lab Med 2003;127:946-9.

(Accepted 14 December 2005)

doi $10.1136 /$ bmj.38701.440961.7C

\title{
Risk factors for pulmonary tuberculosis in Russia: case-control study
}

Richard Coker, Martin McKee, Rifat Atun, Boika Dimitrova, Ekaterina Dodonova, Sergei Kuznetsov, Francis Drobniewski

\begin{abstract}
Objectives To determine risk factors for pulmonary tuberculosis in Russia.

Design Case-control study of exposure to a variety of risk factors before and during the development of pulmonary tuberculosis.

Setting Large city in Russia.

Participants Cases were 334 consecutive adults diagnosed as having culture confirmed pulmonary tuberculosis between 1 January 2003 and 31 December 2003. Controls were 334 individuals sampled from a validated population registry, matched for age and sex to the patients with tuberculosis. A questionnaire collected information on potential risk factors.

Main outcome measures Risk factors associated with the development of tuberculosis.

Results The main risk factors for tuberculosis were low accumulated wealth (univariate odds ratio 16.70), financial insecurity (5.67), consumption of unpasteurised milk (3.58), diabetes (2.66), living with a relative with tuberculosis (2.94), being unemployed (6.10), living in overcrowded conditions (2.99), illicit drug use (8.74), and a history of incarceration in both pretrial detention centres (5.70) and prison (12.50). Conclusions When prevalence of exposure is taken into account the most important factors in the development of pulmonary tuberculosis in Russia are exposure to raw milk and unemployment.
\end{abstract}

\section{Introduction}

Rates of tuberculosis in Russia have increased since the break-up of the Soviet Union, but little is known about the risk factors for developing the disease. This case-control study aimed to determine the risk factors for pulmonary tuberculosis in adults in a region of Russia where changes in rates of tuberculosis have mirrored those for the country as a whole.

\section{Methods}

We undertook a case-control study in the city of Samara, 700 miles southeast of Moscow. All participants were residents of the city. We defined cases as all adults with culture confirmed pulmonary tuberculosis newly diagnosed at any of the city's specialist tuberculosis clinics between 1 January 2003 and 31 December 2003, and recruited to a WHO DOTS (directly observed treatment short course) programme. We estimated that 307 cases and an equal number of controls should be recruited to achieve $80 \%$ power to detect an odds ratio of 2.0 at the $5 \%$ significance level if $10 \%$ or more of the general population were exposed to the risk factor. Controls were sampled randomly from the general population of Samara city; they were matched for year of birth and sex, and they had no history of tuberculosis. A team of 22 trained interviewers administered a previously piloted questionnaire to

This article was posted on bmj.com on 8 December 2005: http://bmj.com/cgi/doi/10.1136/bmj.38684.687940.80
European Centre on Health of Societies in Transition, Department of Public Health and Policy, London School of Hygiene and Tropical Medicine, London WC1E 7HT Richard Coker reader

Martin McKee professor

Boika Dimitrova research fellow

Tanaka Business School, Imperial College London, London Rifat Atun reader

Samara Social Research Institute, Samara, Russia

Ekaterina Dodonova research fellow

Samara Oblast Health Department, Samara

Sergei Kuznetsov head of department of adult healthcare continued over BMJ 2006;332:85-7 
Mycobacterium Reference Unit, Institute of Cell and Molecular Sciences, Queen Mary's School of Medicine,

London

Francis

Drobniewski

professor

Correspondence to: R Coker

richard.coker@

lshtm.ac.uk

Odds ratios (95\% confidence intervals) for risk factors for tuberculosis in Russia

\begin{tabular}{|c|c|c|c|c|c|}
\hline Variable & Univariate & $\begin{array}{l}\text { Adjusted for diabetes } \\
\text { and exposure }\end{array}$ & $\begin{array}{l}\text { Adjusted for assets } \\
\text { and overcrowding }\end{array}$ & $\begin{array}{l}\text { Adjusted for } \\
\text { employment and } \\
\text { financial security }\end{array}$ & $\begin{array}{l}\text { All variables } \\
\text { together }\end{array}$ \\
\hline \multicolumn{6}{|l|}{ Diabetes: } \\
\hline No & 1.00 & 1.00 & NA & NA & 1.00 \\
\hline Yes & 2.66 (1.10 to 6.46$)$ & & & & 7.83 (2.37 to 25.89$)$ \\
\hline \multicolumn{6}{|c|}{ Relative with tuberculosis: } \\
\hline No & 1.00 & 1.00 & NA & NA & 1.00 \\
\hline Yes & 2.94 (1.79 to 4.85$)$ & & & & 2.80 (1.47 to 5.36$)$ \\
\hline \multicolumn{6}{|c|}{ Drinking raw milk: } \\
\hline No & 1.00 & 1.00 & & NA & 1.00 \\
\hline Yes & 3.58 (2.58 to 4.97$)$ & & & & 2.75 (1.80 to 4.20$)$ \\
\hline \multicolumn{6}{|l|}{ Assets: } \\
\hline Most & 1.00 & 1.00 & NA & NA & 1.00 \\
\hline 2 & 1.14 (0.67 to 1.96$)$ & 1.21 (0.69 to 2.14$)$ & & & 1.08 (0.56 to 2.07$)$ \\
\hline 3 & 5.45 (3.14 to 9.46$)$ & 5.36 (2.98 to 9.63$)$ & & & 3.56 (1.78 to 7.12 ) \\
\hline 4 & 6.05 (3.58 to 10.22) & 6.20 (3.56 to 10.82) & & & 3.58 (1.83 to 7.01$)$ \\
\hline Least & 16.70 (8.87 to 31.43$)$ & 16.40 (8.40 to 32.02$)$ & & & 8.82 (4.04 to 19.26$)$ \\
\hline \multicolumn{6}{|c|}{ Living space/person: } \\
\hline Most & 1.00 & 1.00 & NA & NA & 1.00 \\
\hline 2 & 1.04 (0.67 to 1.62$)$ & 1.28 (0.80 to 2.06$)$ & & & $1.74(0.95$ to 3.20$)$ \\
\hline 3 & 1.24 (0.80 to 1.94$)$ & 1.28 (0.79 to 2.06$)$ & & & 1.89 (1.03 to 3.47$)$ \\
\hline Least & 2.99 (1.92 to 4.68$)$ & 3.48 (2.15 to 5.63$)$ & & & 3.77 (2.06 to 6.88 ) \\
\hline \multicolumn{6}{|l|}{ Employed: } \\
\hline Yes & 1.00 & 1.00 & 1.00 & NA & 1.00 \\
\hline No & 6.10 (4.32 to 8.61$)$ & 6.33 (4.38 to 9.15$)$ & 5.93 (3.91 to 8.99) & & 5.84 (3.79 to 9.01 ) \\
\hline
\end{tabular}

Shortage of food:

\begin{tabular}{lllll}
\hline No & 1.00 & 1.00 & NA
\end{tabular}

\begin{tabular}{lcc}
\hline Yes & $2.72(1.56$ to 4.74$)$ & $2.11(1.17$ to 3.82$)$ \\
\hline Financial security: & &
\end{tabular}

\begin{tabular}{llllll}
\hline Most & 1.00 & 1.00 & 1.00 & NA & \\
\hline 2 & $0.55(0.33$ to 0.92$)$ & $0.55(0.33$ to 0.94$)$ & $0.47(0.26$ to 0.85$)$ & $0.46(0.24$ to 0.89$)$ \\
\hline 3 & $2.33(1.45$ to 3.73$)$ & $2.18(1.33$ to 3.58$)$ & $1.55(0.87$ to 2.72$)$ & $1.60(0.86$ to 2.95$)$ \\
\hline 4 & $1.97(1.27$ to 3.06$)$ & $1.80(1.13$ to 1.86$)$ & $1.08(0.62$ to 1.86$)$ & $0.90(0.50$ to 1.63$)$ \\
\hline Least & $5.67(3.29$ to 9.76$)$ & $5.00(2.84$ to 8.82$)$ & $1.82(0.96$ to 3.42$)$ & $1.60(0.79$ to 3.21$)$ \\
\hline
\end{tabular}

Current smoking (cigarettes/day):

\begin{tabular}{|c|c|c|c|c|c|}
\hline None & 1.00 & 1.00 & NA & NA & NA \\
\hline $1-2$ & 3.76 (1.15 to 12.30$)$ & 2.89 (0.83 to 10.05$)$ & & & \\
\hline $3-10$ & 2.29 (1.47 to 3.57$)$ & 2.29 (1.43 to 3.68$)$ & & & \\
\hline $11-20$ & 1.90 (1.34 to 2.70$)$ & 1.87 (1.28 to 2.73$)$ & & & \\
\hline$>20$ & 1.13 (0.51 to 2.48$)$ & 1.00 (0.43 to 2.33$)$ & & & \\
\hline \multicolumn{6}{|c|}{ Heavy drinking at least once/month in past year: } \\
\hline No & 1.00 & 1.00 & NA & NA & NA \\
\hline Yes & 2.89 (1.50 to 5.56$)$ & 2.43 (1.22 to 4.85$)$ & & & \\
\hline \multicolumn{6}{|c|}{ Ever used illicit drugs: } \\
\hline No & 1.00 & 1.00 & 1.00 & 1.00 & 1.00 \\
\hline Yes & 8.74 (3.06 to 25.01) & 7.94 (2.71 to 23.29) & 8.67 (2.79 to 26.96) & 5.96 (1.85 to 19.22$)$ & 5.17 (1.55 to 17.26$)$ \\
\hline \multicolumn{6}{|c|}{ History of being in pretrial detention centre: } \\
\hline No & 1.00 & 1.00 & 1.00 & 1.00 & 1.00 \\
\hline Yes & 5.70 (2.63 to 12.36$)$ & 5.17 (2.32 to 11.49$)$ & 4.52 (1.82 to 11.22$)$ & 4.74 (1.80 to 11.63$)$ & \\
\hline \multicolumn{6}{|c|}{ History of being in prison: } \\
\hline No & 1.00 & 1.00 & 1.00 & 1.00 & 1.00 \\
\hline Yes & 12.50 (3.80 to 41.13$)$ & 11.23 (3.34 to 37.80$)$ & 6.96 (1.88 to 25.79$)$ & 7.75 (2.07 to 29.04$)$ & 6.74 (1.74 to 26.06) \\
\hline
\end{tabular}

$\mathrm{NA}=$ not appropriate

potential cases and controls in healthcare facilities or in their own homes. We used conditional logistic regression to analyse the data and take account of the matching for age and sex.

\section{Results}

We recruited 334 cases and 334 age and sex matched controls. Two measures of socioeconomic position were generated (table). The first was a measure of accumulated wealth, developed from responses to questions about the possession of a range of household assets. The second was a measure of financial security: respondents were asked whether they had gone without things that they really needed during the past 12 months. Those with the fewest assets had almost a 17 -fold higher risk than those with the most. Risk was substantially higher among those with a prison or detention centre history (univariate odds ratios 12.50 and 5.70 , respectively) or those who had used illicit drugs (8.74). Unemployment was also associated with a substantially increased risk (6.10), whereas financial insecurity had less of an effect (1.97 for least secure group). The risk of infection was more than three times higher among those who had drunk raw milk (3.58) and almost three times higher among those who had 
diabetes (2.66) or who were living with a relative with tuberculosis (2.94).

Although the figures should be interpreted with considerable caution because of the small numbers involved, it is possible to calculate estimates of the population attributable risk by applying the odds ratios obtained to the prevalence of exposure in the controls (clearly the controls are not a random sample of the population, but we could not obtain population based figures for the variables in question). Calculations using the univariate odds ratios yield population attributable risks of $0.8 \%$ and $2 \%$ for having been in prison or a pretrial detention centre, respectively. However, because of the much higher prevalence of exposure to raw milk, the population attributable risk for this factor was $18 \%$; similarly, that for being unemployed was $28 \%$.

\section{Discussion}

Our findings measure the risks associated with a variety of social factors and tuberculosis. Poverty, unemployment, drinking unpasteurised milk, diabetes, living with a relative with tuberculosis, living in overcrowded conditions, and a prison or detention history were independently associated with an increased risk of tuberculosis.

Research has shown that a history of imprisonment is strongly associated with tuberculosis but did not examine the role of pretrial detention centres, unpasteurised milk, or diabetes. ${ }^{1}$ Others have drawn attention to the role of the criminal justice system, specifically pretrial detention centres, in the epidemic of tuberculosis in Russia but did not measure this association. ${ }^{2}{ }^{3}$ Our study confirms that incarceration is associated with a substantial increase in the risk of pulmonary tuberculosis. However, the small size of the population attributable risks associated with the two forms of incarceration suggest that, contrary to common belief, imprisonment-before trial or after sentencing-does not contribute greatly to the overall burden of tuberculosis in Russia.

The association found with unpasteurised milk may be linked to Mycobacterium bovis infection. The dairy industry has been affected by the political transition, and the consumption of unpasteurised milk has increased. ${ }^{45}$ If the association between drinking raw milk and tuberculosis proves to be related to $M$ bovis, ensuring a safe milk supply would be a public health priority.

Our study has several limitations. Although living with a relative who had tuberculosis was associated with a greater risk, recall bias is possible. We did not investigate the potential role of HIV because of ethical, political, and practical considerations. Although HIV infection may be an important but unexplored risk factor, this is a recent phenomenon, and as yet the degree of immune suppression in infected individuals is not marked. $^{6}$

We thank David Leon of the London School of Hygiene and Tropical Medicine for methodological advice.

Contributors: RC, MM, and BD designed the study; RC, MM, RA, BD, ED, SK, and FD supervised data collection and analysis; $\mathrm{RC}, \mathrm{MM}, \mathrm{RA}$, and FD wrote the report. RC is guarantor.

\section{What is already known on this topic}

Rates of tuberculosis have increased greatly in Russia over the past decade

Most research has examined the factors associated with the emergence of multidrug resistant tuberculosis or described the profiles of cases of tuberculosis

\section{What this study adds}

Exposure to raw milk and unemployment are probably the most important contributors to the burden of tuberculosis in the population studied

Other major risk factors for tuberculosis in Russia are poverty, overcrowding, illicit drug use, living with a relative with tuberculosis, and imprisonment-either before trial or after sentencing

Funding: The UK Department for International Development (DFID) funded this study, but the views and opinions expressed are those of the authors alone.

Competing interests: None declared.

Ethical approval: Ethics committees of London School of Hygiene and Tropical Medicine and Samara Health Ministry.

1 Tekkel M, Rahu M, Lioit H-M, Baburin A. Risk factors for pulmonary tuberculosis in Estonia. Int J Tuberc Lung Dis 2002;6:887-94.

2 Stern V, ed. Sentenced to die? The problems of TB in prisons in Eastern Europe and Central Asia. London: International Centre for Prison Studies, 1999. Farmer PE, Kononets AS, Borisov SE, Goldfarb A, Healing T, MCKee M Farmer PE, Kononets AS, Borisov SE, Goldfarb A, Healing T, McKee M. Recrudescent tuberculosis in the Russian Federation. In: Farmer PE, Reichman LB, Iseman MD, eds. The global impact of drug resistant tuberculosis. Boston, MA: Harvard Medical School/Open Society Institute, 1999. 4 Milk production/processing. Food and Agriculture Organization of the United Nations, Investment Centre, 1999. (Agribusiness handbooks. Vol. 7.) Rome: FAO.

5 Tulupov VP. Hygienic problems of allocating and planning for milk pasteurization and processing plants at subsidiary farms (Russian). Gig Sanit 1989;12:68-70.

6 Drobniewski F, Atun R, Fedorin I, Bykov A, Coker RJ. 'Bear trap': the colliding epidemics of multidrug resistant tuberculosis and HIV in Russia. Int J STD AIDS 2004;15:641-6.

(Accepted 9 September 2005)

doi 10.1136/bmj.38684.687940.80

\section{Corrections and clarifications}

\section{Qualities of a surgeon}

In this Endpiece filler article by $\mathrm{S} N$ Anjum and colleagues (BMJ 2005;331:1176, 19 Nov) we should probably have used the Latin spelling for the name of the Roman medical writer Aulus Cornelius Celsus (c 25 BC to AD 50)-not Celsius (Anders Celsius, 1701-1744), who, as one respondent pointed out, "has got a lot to do with thermometers [rather than] qualities as a surgeon."

MPs accuse Medical Research Council of panic over bird flu

During the editorial process, we introduced an error into the opening paragraph of this News article by Michael Day (BMJ 2005;331:1358, 10 Dec). The UK Medical Research Council was reporting about avian influenza to the House of Commons [not the House of Lords, as we stated] Select Committee on Science and Technology. The confusion arose because of a separate, ongoing inquiry into pandemic flu in the House of Lords. 